\title{
Cutaneous Adnexal Cysts Revisited: What We Know and What We Think We Know
}

\author{
Gürkan Kaya $^{a}$ Jean-Hilaire Saurat ${ }^{b}$ \\ a'Department of Dermatology, University Hospital of Geneva, Geneva, Switzerland; \\ ${ }^{b}$ Department of Pharmacology and Toxicology, University of Geneva, Geneva, Switzerland
}

\author{
Keywords \\ Cutaneous cysts · Classification · Cytokeratin
}

\begin{abstract}
Cutaneous cysts have been classified by dermatopathologists in many different ways. Here, we propose a novel classification of cutaneous adnexal cysts according to their origin in the folliculosebaceous unit and the sweat glands. By examining the lining of the cystic structure, its origin can be easily identified. Epidermal cysts have an epithelial wall containing a granular layer with lamellar keratinization, indicating an infundibular origin. Tricholemmal cysts have an undulating epithelial wall with no granular layer and a compact keratinization, showing an isthmic origin. In steatocystoma, dermoid cyst, and folliculosebaceous hamartoma, the epithelial lining shows a crenulated appearance which is seen in the sebaceous duct. Hidrocystoma shows the characteristic cuboidal epithelial lining of sweat glands with decapitation secretion in its apocrine forms. The hair matrix cyst wall is composed of basaloid cells maturing to squamoid cells, as seen in the normal hair matrix and shadow cells in the lumen. Metabolizing acquired dioxin-induced skin hamartoma (MADISH) is a cystic lesion with lamellar keratinization, and no sebaceous glands. The classification proposed here aims to simplify the complexity of cutaneous adnexal cysts, and to facilitate a better understanding of the origin of cystic lesions of the skin.




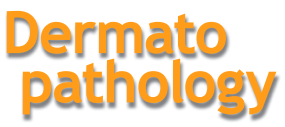

Table 1. Classification of cutaneous cysts according to Weedon [1]

Table 2. Classification of cutaneous cysts according to McKee [2]

\begin{tabular}{|c|c|}
\hline Dermatopathology 2018 & \\
\hline DOI: $10.1159 / 000488585$ & $\begin{array}{l}\text { (c) } 2018 \text { The Author(s). Published by S. Karger AG, Basel } \\
\text { www.karger.com/dpa }\end{array}$ \\
\hline
\end{tabular}

Kaya and Saurat: Cutaneous Adnexal Cysts Revisited

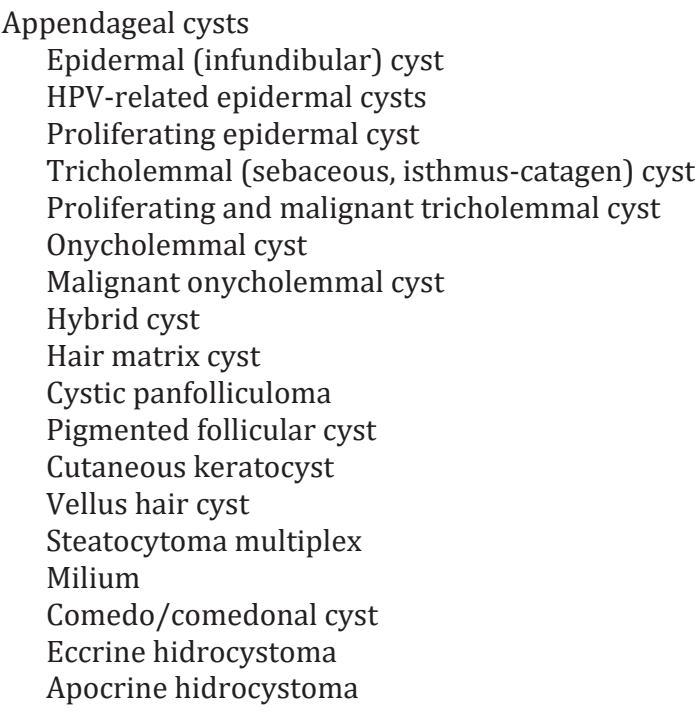

This classification is taken from chapter 16: "Cysts, Sinuses and Pits" [1]. 
Table 3. Classification of skin cysts according to Rapini [3]

\author{
Epidermoid cyst \\ Pilar cyst \\ Dermoid cyst \\ Vellus hair cyst \\ Steatocystoma \\ Cervical thymic cyst \\ Cutaneous ciliated cyst \\ Thyroglossal duct cyst \\ Branchial cleft cyst \\ Bronchogenic cyst \\ Hidrocystoma \\ Median raphe cyst of the penis \\ Auricular pseudocyst
}

This classification is taken from chapter 19: "Cysts" [3].

(Table 3). Barnhill [4] is the only author cited here who classifies cutaneous cysts according to the types of cells in their wall lining (Table 4).

We propose a novel classification of cutaneous adnexal cysts according to their origin in the folliculosebaceous unit and sweat glands (Table 5; Fig. 1). This classification is in accordance with the cytokeratin expression profile of these cysts (Table 6).

\section{Discussion}

Cutaneous cysts have been classified by many prominent dermatopathologists in different ways as explained above. Here, we have proposed a novel classification of cutaneous adnexal cysts according to their origin in the folliculosebaceous unit and sweat glands. By examining the lining of the cystic structure, its origin can be easily identified. Epidermal cysts have an epithelial wall containing a granular layer, and the keratinization through the lumen is lamellar, indicating an infundibular origin (Fig. 2a, b). Tricholemmal cysts have an undulating epithelial wall with no granular layer and a compact keratinization, showing an isthmic origin (Fig. 2c, d). In steatocystoma, dermoid cyst, and folliculosebaceous hamartoma, the epithelial lining shows a crenulated appearance which is seen in the sebaceous duct (Fig. 2e, f, k-n). Hidrocystoma shows the characteristic cuboidal epithelial lining of sweat glands with decapitation secretion in its apocrine form (Fig. $2 \mathrm{~g}, \mathrm{~h}$ ). The hair matrix cyst wall is composed of basaloid cells maturing to squamoid cells, as seen in the normal hair matrix and shadow cells in the lumen (Fig. 2i, j). Metabolizing acquired dioxin-induced skin hamartoma (MADISH) is a cystic lesion with no sebaceous glands, and shows lamellar keratinization [5, 6] (Fig. 2o, p).

The cytokeratin expression pattern is also consistent with the origin of the cyst. For example, the sebaceous-duct keratin, CK17, is expressed in steatocystoma, dermoid cyst, and folliculosebaceous hamartoma. Epidermal cysts express CK10 as do tricholemmal cysts, which also express CK17. Eccrine and apocrine hidrocystomas show broader expression of cytokeratins (CK1, CK5, CK7, CK8, CK10, CK14, CK18, and CK19). CK16 is only expressed by folliculosebaceous hamartoma [7-9]. In MADISH, as in folliculosebaceous hamartoma, CK15 is expressed (Table 6). The hair matrix cyst, often diagnosed as a part of a follicular hybrid cyst (e.g., epidermal and/or tricholemmal cyst) does not express any cytokeratins [10]; however, the wall of the cyst shows a strong positivity for $\beta$-catenin [11]. 


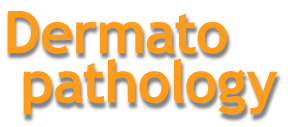

Table 4. Classification of cutaneous cysts according to Barnhill [4]

Table 5. Our proposed novel classification of cutaneous adnexal cysts (c) 2018 The Author(s). Published by S. Karger AG, Basel www.karger.com/dpa

Kaya and Saurat: Cutaneous Adnexal Cysts Revisited

Epithelial-lined cysts

Stratified squamous

Epidermoid (infundibular) cyst

Pilar (tricholemmal) cyst

Vellus hair cyst

Milia

Follicular hybrid cyst

Pigmented follicular cyst

Stratified squamous with components in cyst wall

Steatocystoma (simplex and multiplex)

Dermoid cyst

Thymic cyst

Cuboidal

Eccrine hidrocystoma

Apocrine hidrocystoma

Mixed squamous and nonsquamous ciliated

Bronchogenic cyst

Brachial cleft cyst

Thyroglossal duct cyst

Cutaneous ciliated cyst

Ciliated cyst of vulva

Omphalomesenteric cyst

Pseudostratified columnar

Median raphe cyst

Cysts not lined by an epithelium

Digital mucous cyst

Mucocele

Metaplastic synovial cyst

Pilonidal cyst

Pseudocyst of auricle

New entities

Proliferating epithelial cyst

This classification is taken from chapter 25: "Cutaneous Cysts and Related Lesions (Table 25-1: Classification of cutaneous cysts)" [4].

Cysts with infundibular epithelial wall

Epidermal (infundibular) cyst

Comedon

Milia

Vellus hair cyst

Cysts with isthmic epithelial wall

Tricholemmal cyst

Cysts with sebaceous duct epithelial wall

Steatocystoma

Cutaneous keratocyst

Cysts with glandular epithelial wall Eccrine/apocrine hidrocystoma

Cysts with hair matrix epithelial wall Hair matrix (pilomatrical) cyst

Hamartomatous cysts

Dermoid cyst

Folliculosebaceous hamartoma

MADISH (metabolizing acquired dioxin-induced skin hamartoma) 
Table 6. Cytokeratin expression of different cutaneous adnexal cysts (see Table 5)

\begin{tabular}{|c|c|c|c|c|c|c|c|c|c|c|c|}
\hline & CK1 & CK5 & CK7 & CK8 & CK10 & CK14 & CK15 & CK16 & CK17 & CK18 & CK19 \\
\hline Epidermal cyst & & & & & + & & & & & & \\
\hline Vellus hair cyst & + & & & & + & & & & + & & \\
\hline Tricholemmal cyst & & & & & + & & & & + & & \\
\hline Steatocystoma & & & & & + & & & & + & & \\
\hline Hidrocystoma eccrine & + & + & & & + & + & & & & & \\
\hline Hidrocystoma apocrine & & & + & + & & & & & & + & + \\
\hline Dermoid cyst & + & & & & + & + & & & + & & \\
\hline Folliculosebaceous & & & & & & & & & & & \\
\hline hamartoma & + & & & & + & & + & + & + & & \\
\hline MADISH & & & & & & & + & & & & \\
\hline
\end{tabular}

Fig. 1. Proposed novel classification of cutaneous adnexal cysts according to their origin in the folliculosebaceous unit and sweat glands.

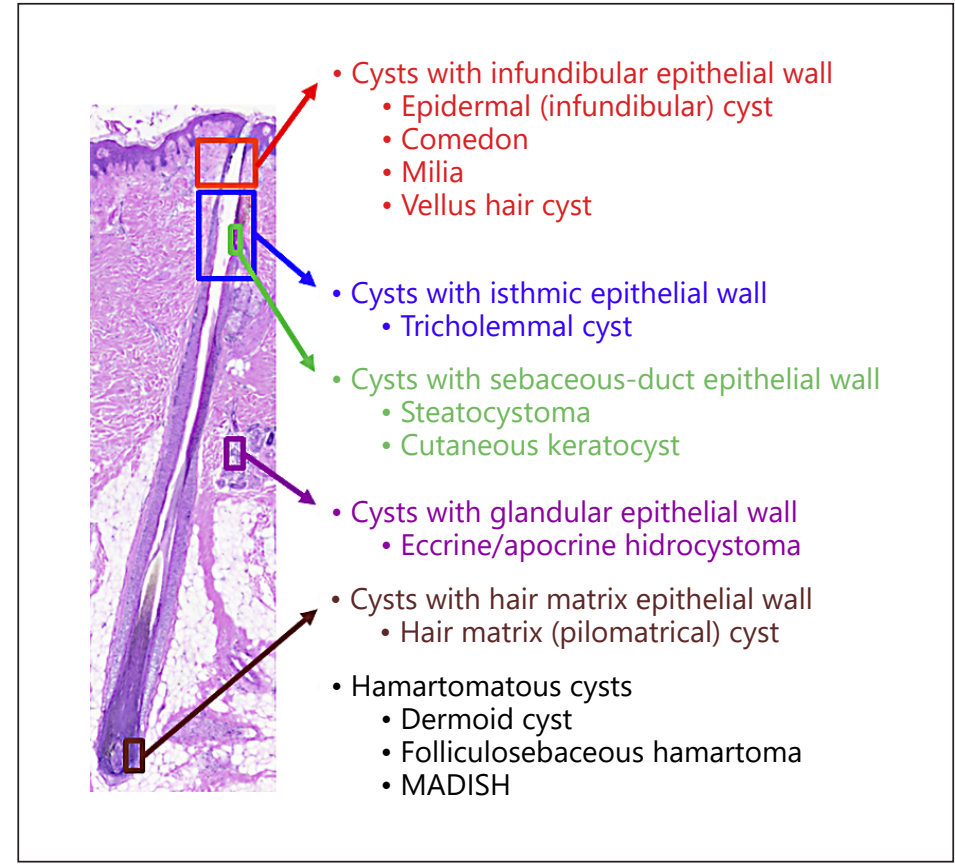

The follicular stem cell marker Lrig1 is expressed at the isthmic region of the human folliculosebaceous unit [12], and the activation of $\beta$-catenin in Lrig1-positive stem cells gives rise to cystic proliferations that are reminiscent of MADISH in mice [13].

Trichoblastic infundibular cyst, cystic trichoblastoma, cystic panfolliculoma, dermoid cyst with basaloid proliferations, folliculosebaceous cystic hamartoma, and BCC occurring in infundibular cysts have also been classified differentially [14]. Recently, cutaneous keratocyst and steatocystoma, unified as sebaceous-duct cyst, have been proposed to be a hamartoma resembling the sebaceous duct $[15,16]$.

The classification proposed here aims to simplify the complexity of cutaneous adnexal cysts and facilitate a better understanding of the origin of the cystic lesions of the skin. 


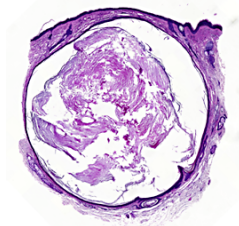

a
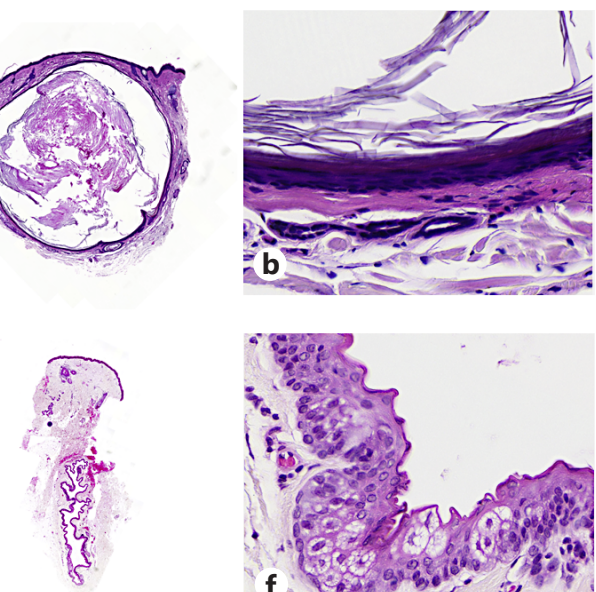

e
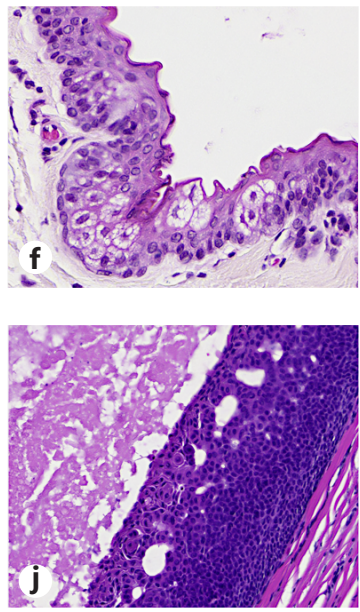

i
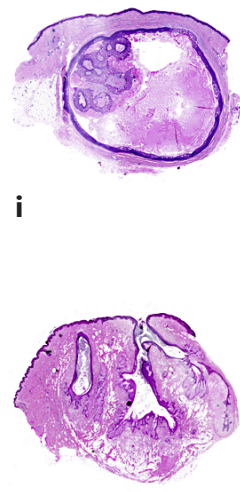

m

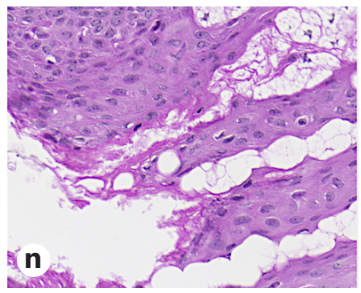

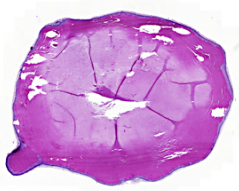

C

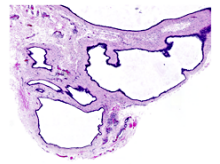

g
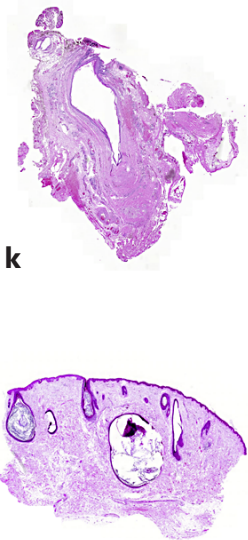
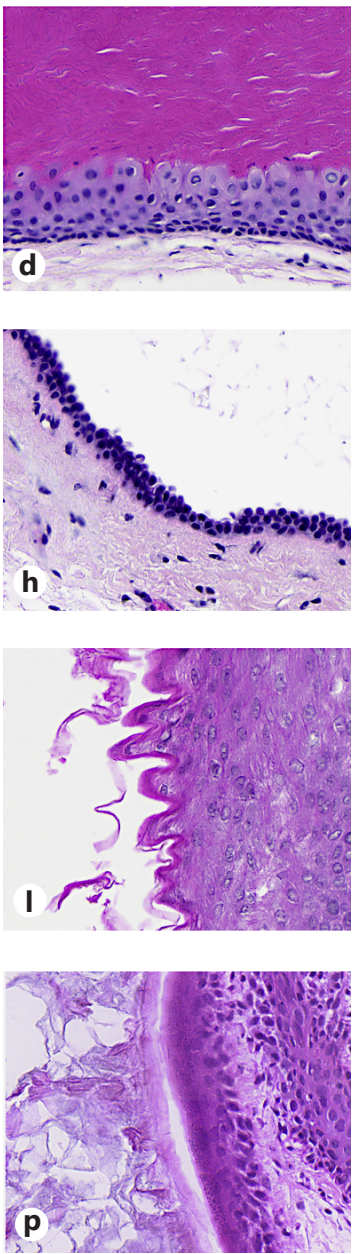

Fig. 2. Epidermal cyst (a), tricholemmal cyst (c), steatocystoma (e), hidrocystoma (g), hair matrix cyst (i), dermoid cyst $(\mathbf{k})$, folliculosebaceous hamartoma $(\mathbf{m})$, and MADISH $(\mathbf{o}) . \times 1$. Close-up of sections shows the epithelial lining with a granular layer and lamellar keratinization $(\mathbf{b}, \mathbf{p})$, undulation and tricholemmal keratinization with no granular layer (d), crenulation with sebaceous-duct-type keratinization (f, I, n), cuboidal cells with apocrine-type secretion (h), and basaloid cells with maturation to squamoid cells (j). $\times 40$.

\section{Disclosure Statement}

The authors have no conflict of interest to declare.

\section{References}

Weedon D: Weedon's Skin Pathology, ed 3. London, Churchill Livingstone, 2010.

McKee PH (ed): McKee's Pathology of the Skin, ed 4. Edinburgh, Elsevier/Saunders, 2012.

Rapini RP: Practical Dermatopathology. Edinburgh, Elsevier/Saunders, 2012.

Barnhill RL (ed): Dermatopathology, ed 3. New York, McGraw Hill, 2010.

5 Saurat JH, Kaya G, Saxer-Sekulic N, Pardo B, Becker M, Fontao L, et al: The cutaneous lesions of dioxin exposure: lessons from the poisoning of V. Yushchenko. Toxicol Sci 2012;125:310-317. 
6 Fabbrocini G, Kaya G, Caseiro Silverio P, De Vita V, Kaya A, Fontao F, et al: Aryl hydrocarbon receptor activation in acne vulgaris skin: a case series from the region of Naples, Italy. Dermatology 2015;231:334-338.

7 Kurokawa I, Nishijima S, Kusumoto K, Senzaki H, Shikata N, Tsubura A: Cytokeratin expression in steatocystoma multiplex. Br J Dermatol 2002;146:534-536.

-8 Tomková H, Fujimoto W, Arata J: Expression of keratins (K10 and K17) in steatocystoma multiplex, eruptive vellus hair cysts, and epidermoid and trichilemmal cysts. Am J Dermatopathol 1997;19:250-253.

-9 Kurokawa I, Nishimura K, Hakamada A, Isoda K, Yamanaka K, Mizutani H, Tsubura A: Cutaneous dermoid cyst: cytokeratin and filaggrin expression suggesting differentiation towards follicular infundibulum and mature sebaceous gland. Oncol Rep 2006;16:295-299.

10 Tsuji N, Kurokawa I, Tokime K, Omoto Y, Senba Y, Habe K, et al: Epidermal cyst with pilomatricoma (follicular hybrid cyst): immunohistochemical study with epithelial keratins and filaggrin. J Dermatol 2010;37:922-925.

11 Rodins K, Baillie L: Hybrid follicular cyst (pilomatrical and infundibular) arising within a sebaceous nevus. Pediatr Dermatol 2012;29:213-216.

12 Barnes L, Puenchera J, Saurat JH, Kaya G: Lrig1 and CD44v3 expression in the human folliculosebaceous unit. Dermatology 2015;231:116-118.

13 Kretzschmar K, Weber C, Driskell RR, Calonje E, Watt FM: Compartmentalized epidermal activation of $\beta$-catenin differentially affects lineage reprogramming and underlies tumor heterogeneity. Cell Rep 2016;14:269281.

14 López-Takegami JC, Wolter M, Löser C, Maiweg C, Jones M, Metze D, Böer-Auer A: Classification of cysts with follicular germinative differentiation. J Cutan Pathol 2016;43:191-199.

15 Makhija M: Cutaneous keratocyst and steatocystoma unified as sebaceous duct cyst, a hamartoma resembling the sebaceous duct. Am J Dermatopathol 2015;37:871-873.

16 Fernandez-Flores A: On steatocystoma, sebaceous duct cyst, isthmic-anagenic cyst, and CK19. Am J Dermatopathol 2015;37:733-734. 